\title{
Antidiabetic effect of the Egyptian honey bee (Apis mellifera) venom in alloxan- induced diabetic rats
}

\author{
Ahmad K. Hassan ${ }^{1 *}$, Dina A. El-kotby ${ }^{1}$, Mohamed M. Tawfik', Rasha E. Badr ${ }^{2}$ and Iman M. Bahgat ${ }^{1}$
}

\begin{abstract}
Background: Diabetes mellitus (DM) is one of the most common endocrinal diseases characterized by hyperglycemia and altered metabolism of lipids, carbohydrates, and proteins with an increased risk of many complications. Bioactive drugs extracted from natural sources had been used in a wide range of treatment for many diseases. This work aimed to investigate the potential antidiabetic effect of Egyptian honey bee venom (BV) in alloxan-induced diabetic rats.
\end{abstract}

Subjects and methods: Forty adult male albino rats (140-180 g) were used in the study and divided into five groups each of eight rats. The normal control group, diabetic group, high- and low-dose BV-treated groups, and vildagliptintreated group. Blood samples and pancreases were collected after 6 weeks of the experiment.

Results: Treatment of diabetic rats with BV revealed a significant decrease in serum glucose level accompanied by a significant increase in insulin level. Malondialdehyde (MDA), cholesterol, triglycerides, creatinine, and aminotransferases (ALT and AST) levels were significantly decreased after BV treatment in comparison with diabetic animals. Total antioxidant capacity (TAC), glutathione (GSH) contents, and catalase (CAT) activity had improved. Histological examination of the pancreas indicated a marked improvement in the islet architecture and marked regeneration of insulin-secreting $\beta$-cell in diabetic BV-treated rats.

Conclusion: The study concluded that BV could have the ability to lower glucose level in diabetic rats and enhance insulin secretion, and relieved the various biochemical and histological abnormalities resulted due to diabetes metabolic disorders.

Keywords: Bee venom, Diabetes, Antioxidants, Pancreas, MDA

\section{Background}

$\mathrm{DM}$ is a critical disease, due to the rapid rise of diagnosed patients to be in the diabetic pool especially in the last two decades (Sandu et al., 2016). Unfortunately, DM is growing more in the low- to middle-income world than in high-income one (World Health Organization, 2016). As DM is characterized by elevated blood glucose level that if not controlled efficiently will cause end-organ damages in many systems like genitourinary, cardiovascular, neurological, and also the eyes (Park \& Jang, 2017) All of these characters make DM a challenge that in need of an efficient and longstanding medical care which can control elevated blood glucose level and

\footnotetext{
* Correspondence: ahkhalaf71@yahoo.com

'Zoology Department, Faculty of Science, Port Said University, 23rd

December Street, Port Said 42515, Egypt

Full list of author information is available at the end of the article
}

also extends to prevent such a complications (American Diabetes Association, 2017).

Insulin is not the only treatment of DM; there were many known oral medications that help to lower elevated blood glucose levels such as glucagon-like peptide-1 receptor agonists and dipeptidyl peptidase 4 inhibitors (Thakare, Shende, Shirure, \& Swami, 2017). Mostly, these drugs have adverse unwanted effects which necessitate the need for new modalities like natural products to replace those (Hossen, Gan, \& Khalil, 2017). Great attention has been paid lately to the venomous products of some animals in the development of treatments for many diseases; one of them is DM (Roudbari \& Imani, 2012).

$\mathrm{BV}$ is a combination of peptides (adolapin, apamin, melittin, and mast cell degranulating peptide), enzymes (phosphatase, hyaluronidase, $\alpha$-glucosidase, 
phospholipase B, and phospholipase A2), and low molecular weight components. It also had a non-peptide fraction (histamine, dopamine, and nor-epinephrine) (Raghuraman \& Chattopadhyay, 2007). BV had been used as a drug due to its therapeutic effects on many illnesses like neurological, cardiovascular, hematological, musculoskeletal, and dermatological diseases (Abdela \& Jilo, 2016; Sforcin, Bankova, \& Kuropatnicki, 2017).

The most known cellular oxidants are reactive oxygen species (ROS), free radicals, and reactive nitrogen species (Asmat, Abad, \& Ismail, 2016). Overcoming the oxidants is a critical point that affects cell health, and it depends on antioxidants that counteract the oxidant effects by lagging and or prohibiting oxidation and cellular damages. BV is believed to counteract the antioxidant effects (Roy, Saha, \& Pal, 2015). In a study conducted in 2016, the BV had lowering effects on elevated blood glucose and on dyslipidemia too (Gawad, Fikry, Amin, Elmahdi, \& Elaziz, 2016).

The current study aims to evaluate the potential antidiabetic effect of Egyptian honey bee venom (Apis mellifera) compared with a commercially widely used antidiabetic treatment (vildagliptin). These finding will be useful to drive insights into the use of natural products in Egypt rather than chemically synthetic drugs.

\section{Materials and methods}

\section{Experimental animals}

Forty healthy adult male albino rats, with normal glucose level, weighing about $140-180 \mathrm{~g}$ were used in the current experiment. All animals were housed in polyethylene cages in a well-ventilated room at the Animal House of Zoology Department, Faculty of Science, Port Said University. The animals were kept at the room temperature of $25 \pm 5^{\circ} \mathrm{C}$ under a natural light cycle (12-h dark/light cycle). They were fed standard ordinary commercial rat pellets and water ad libitum. Maintenance and care of the experimental animals were in conformity with the International Guiding Principles for Animal Research.

\section{Bee venom}

BV was purchased as crude form (Faculty of Agricultural Environmental Sciences, Suez Canal University, El-Arish, Egypt).

\section{Induction of diabetes}

Rats were fasted for 1 day and left free to drink water. Alloxan monohydrate (Sigma-Aldrich Chemical, USA) was freshly prepared as a solution to be injected by dissolving in $\mathrm{NaCl}(0.9 \%)$. DM had been induced by a single dose through intraperitoneal injection of alloxan $(120 \mathrm{mg} / \mathrm{kg})$ into fasted rats (Das, Vasan, \& Sil, 2012; Rashid, Das, \& Sil, 2013). The estimation of glucose level was done 3 days after alloxan injection. Rats that had a glucose level equal to $200 \mathrm{mg} / \mathrm{dl}$ or more were considered to be diabetic (Shabeer, Srivastava, \& Singh, 2009; Yadav, Saini, Kalia, \& Dangi, 2008). Then, they were transferred into new cages and had given the treatment according to experimental group design.

\section{Experimental groups and design of the work}

Animals were divided into separate cages and into five treatment groups each of eight animals. Treatment had been applied for successive 6 weeks via intraperitoneal injections as a route of administration. Group "I" was a normal healthy control group that was given a physiological saline solution $(0.9 \% \mathrm{NaCl})$. The other four groups, II, III, IV, and V, were alloxan-induced diabetic animals. Group "II" diabetic (positive control) was left untreated and was just injected daily with $0.9 \% \mathrm{NaCl}$. Groups "III" and "IV" were diabetic and were given BV daily with high dose " $2 \mathrm{mg} / \mathrm{kg}$ " and low dose " $1 \mathrm{mg} / \mathrm{kg}$," respectively; the doses of BV were chosen after a pilot study. Vildagliptin-treated group "V" was diabetic and daily injected with vildagliptin at a dose of $10 \mathrm{mg} / \mathrm{kg}$ (Akarte, Srinivasan, \& Gandhi, 2012).

\section{Biochemical assays}

Blood samples were collected into heparinized tubes for reduced GSH assay. For assaying the glucose level, blood samples were collected into sodium fluoride tubes. For all other parameters, blood was collected in plain tubes. All samples were centrifuged at $3000 \mathrm{rpm}$ for $10 \mathrm{~min}$, and the serum was separated and stored at $-20^{\circ} \mathrm{C}$ until used. ALT, AST, creatinine, total protein, glucose, cholesterol, triglycerides, LDL, and high-density lipoproteins (HDL) were measured using a chemistry autoanalyzer (Roche C111, Boehringer Mannheim Diagnostic, USA) at the Zoology Department, Faculty of Science, Port Said University. Insulin was estimated by using enzyme-linked immune immunosorbent assay (Thermo Scientific, USA). MDA, catalase (CAT), glutathione (GSH) and total antioxidant capacity (TAC) were estimated by the colorimetric method according to the steps of the manufacturer (Sigma-Aldrich "Merck," Germany) on a spectrophotometer (Photometer 5010, Riele GmbH, Germany).

\section{Histopathological section preparation}

Animals were instantly dissected to obtain the pancreas from each animal and rinsed with a saline isotonic solution $(0.9 \% \mathrm{NaCl})$ to remove the excess of blood, cleaned, fixated at $10 \%$ formalin for 1 day, dehydrated, cleared, and then embedded in paraffin wax. The obtained pancreatic tissue blocks had been sectioned by a microtome at a thickness of $5 \mu \mathrm{m}$. After that, all sections were placed on spotless glass slides. Routinely, sections were deparaffinized, rehydrated, and finally stained with 
hematoxylin and eosin dyes. Prepared sections were investigated and pictured with camera microscope system (Olympus BX53, Olympus Corporation, Tokyo, Japan) provided with imaging software (Cell Sense, Version 1.4.1). Pancreatic tissues of the diabetic group were studied against the normal control group and other treatment groups for finding and assessing the histological alterations.

\section{Statistical analysis}

Results were expressed as means \pm standard errors (SE). Data were analyzed statistically using Statistical Package for Social Science (SPSS) version 16 to assess any significant differences between the groups. The potential effects of BV were initially evaluated using one-way analysis of variance (ANOVA) test followed by Tukey's post hoc test for comparison of means with control. Differences between groups of $P^{<} 0.05$ were considered to be statistically significant.

\section{Results}

Regarding the effect of BV on the glucose level, there was a significant decrease in plasma glucose concentration in BV low-dose-treated group, BV high-dose-treated group, and vildagliptin-treated groups $(105 \pm 5.2 \quad P<0.001$, $218.7 \pm 18.9 P<0.04,108.5 \pm 5.8 P<0.001$, respectively) compared with a diabetic group (273.5 \pm 10.9$)$. In both BV low-dose and vildagliptin-treated groups, insulin level was significantly increased $(5.6 \pm 0.17 P<0.002,5.5 \pm 0.31$ $P<0.002$, respectively), while in BV high-dose-treated group, there was none significant increase $(4.39 \pm 0.16$ $P<0.7$; Fig. 1).

Catalase activity was significantly decreased in the diabetic control group $(298 \pm 36.7)$ compared to the normal control group $(975 \pm 64.5 P<0.001)$. In BV low-dose-, BV high-dose-, and vildagliptin-treated groups, CAT activity was increased significantly $(763 \pm 3.8,660.6 \pm 49.3$, $626.4 \pm 24.8 P<0.001)$ compared to the diabetic group. On the other hand, MDA content was significantly increased in the diabetic group $(0.93 \pm 0.12 P<0.002)$ compared to normal group $(0.38 \pm 0.05)$, while it showed a significant decrease in BV low-dose- $(0.44 \pm 0.06)$ and vildagliptin $(0.35 \pm 0.05)$-treated groups versus the diabetic group $(P<0.005$; Fig. 2$)$.

A significant decrease was reported in the GSH level in the diabetic group $(0.51 \pm 0.02)$ compared to the normal group $\left(0.82 \pm 0.06 P^{<} 0.001\right)$. Nevertheless, the GSH level was significantly increased in BV low-dose- and vildagliptin-treated groups versus the diabetic group $(0.79 \pm 0.07,0.75 \pm 0.05 ; P=0.001)$.

TAC content was significantly decreased in the diabetic group $(1.2 \pm 0.22)$ compared to the normal group $(2.5 \pm 0.22 P=0.01)$. There was a significant increase in TAC level in BV high-dose-treated group $(2.96 \pm 0.08)$ compared to the diabetic group $(P=0.002)$. In contrast, there were no significant changes in TAC level between diabetic and BV low-dose- $(1.69 \pm 0.35)$ or vildagliptintreated groups (1.97 $\pm 0.32 P=0.7$; Fig. 2$)$.

As illustrated in Table 1, serum cholesterol and TG contents were significantly decreased in both BV-treated groups $(195 \pm 6.5,191 \pm 2.7$ and $114 \pm 1,126 \pm 1.9)$ and vildagliptin-treated group $(111 \pm 3.4$ and $179 \pm 3.5)$ in comparison to the diabetic group $(201 \pm 8.8$ and $218 \pm 6.5)$ $\left(P^{<} 0.001\right)$. In contrast, there were no significant changes in HDL and LDL contents between the diabetic group (58 \pm 2 and $119 \pm 7.5)$ and BV low-dose-treated group $(70 \pm 1.6$ and $83 \pm 1.4)(P=0.9)$, and vildagliptin-treated group $(77 \pm 2.2$ and $77 \pm 1.2)$ was observed $(P=0.8)$.

Serum AST and ALT was significantly increased in the diabetic group $(96 \pm 2.6$ and $101 \pm 3.9)$ compared to the normal group $(60 \pm 5.1$ and $78 \pm 6.6)(P<0.001)$, while they were significantly decreased in both BV-treated groups
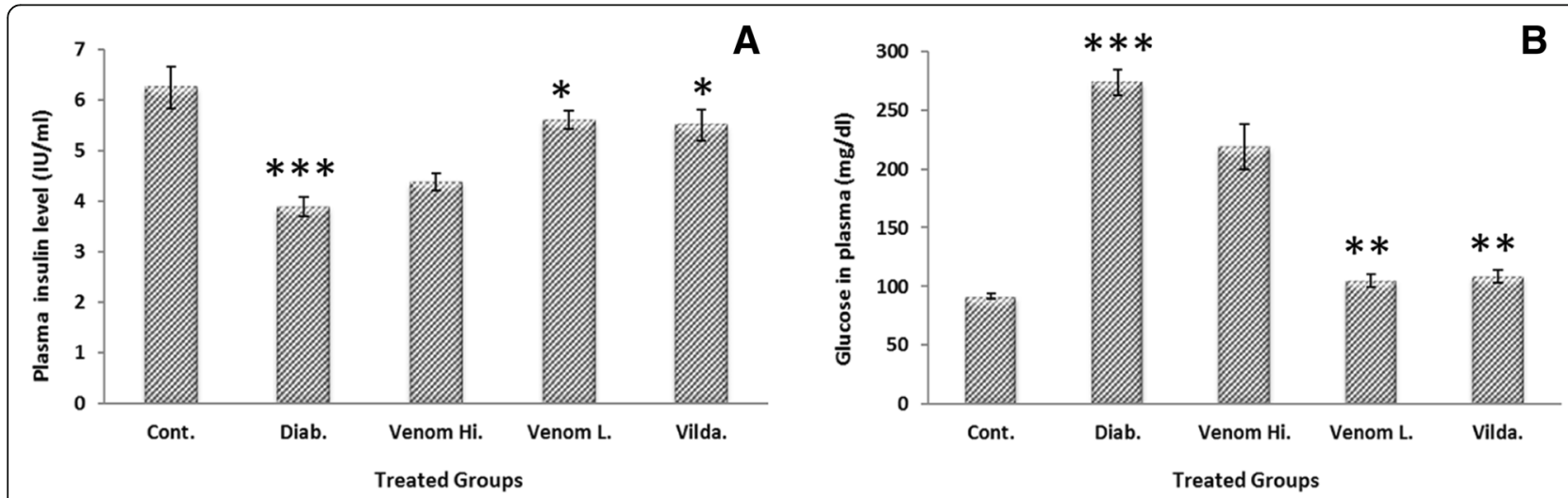

Fig. 1 a Effect of BV and vildagliptin treatment on plasma glucose level. b Effect of BV and vildagliptin treatment on insulin level. One asterisk denotes significant differences in insulin level between BV low dose and vildagliptin groups versus diabetic group. Two asterisks denote significant differences in glucose level between vildagliptin and BV low and BV high doses compared to the diabetic group. Three asterisks denote significant differences in insulin and glucose levels between diabetic and control groups, using one way ANOVA statistical analysis test 


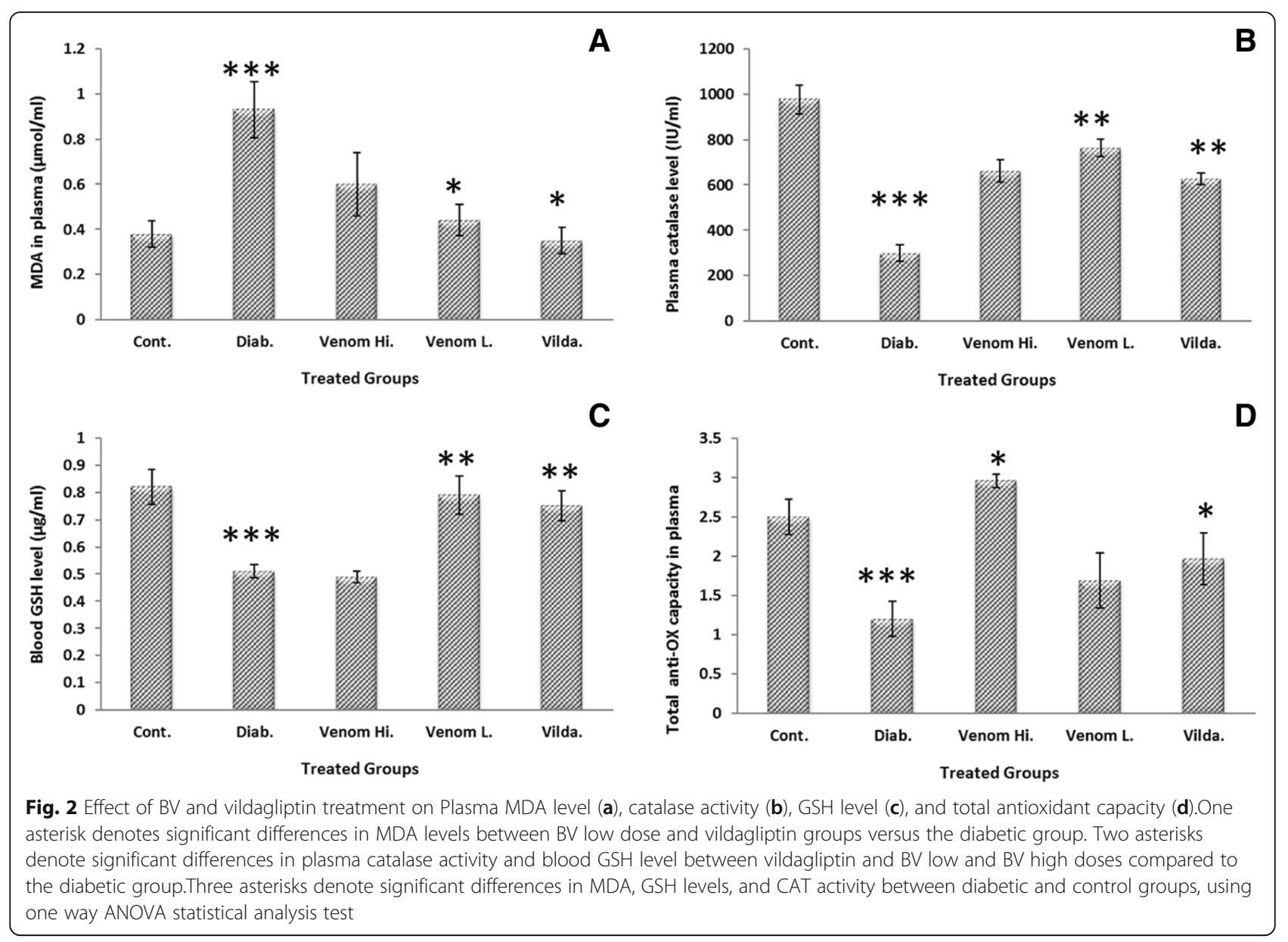

( $60 \pm 3.7,82 \pm 4.3$ and $63 \pm 4.6,77 \pm 6.1)$ as well as in the vildagliptin-treated group $(46 \pm 3.6$ and $76 \pm 4.4)$ compared to the diabetic group $\left(P^{<} 0.001\right)$.

Creatinine was increased significantly in the diabetic group $(1.5 \pm 0.2)$ versus the normal group $(0.74 \pm 0.1) \quad(P<0.007)$. Conversely, it was significantly decreased in BV low-dose$(0.85 \pm 0.09)$ and vildagliptin $(0.7 \pm 0.1)$-treated groups compared to the diabetic group $(P<0.02)$. On the other hand, no significant changes in creatinine level between the diabetic group and BV high-dose-treated group $(1.1 \pm 0.08)$ were observed $(P=0.4)$. There were no significant differences in the total protein between the diabetic and control groups, and all other treated groups $(P=0.4)$ had been reported.

\section{Histopathological examination}

Images were illustrated in Fig. 3 and showed that the normal control group A had a normal structure of pancreatic tissue where pancreatic acini were well distinguishable, islets of Langerhans had a normal spherical shape with a considerable existence of rounded $\beta$-cells

Table 1 Effect of treatment with BV and vildagliptin on biochemical parameters after 6 weeks in diabetic rats

\begin{tabular}{|c|c|c|c|c|c|c|c|c|}
\hline \multirow[t]{2}{*}{ Groups } & \multicolumn{8}{|l|}{ Parameters } \\
\hline & Cholesterol & $\mathrm{TG}$ & $\mathrm{HDL}$ & LDL & ALT & AST & Creat. & $\begin{array}{l}\text { Total } \\
\text { protein }\end{array}$ \\
\hline Control & $179.2 \pm 3.9$ & $103.4 \pm 1.3$ & $89.8 \pm 4.5$ & $68.7 \pm 5.6$ & $78.1 \pm 5.1$ & $60 \pm 5.1$ & $0.74 \pm 0.1$ & $8.1 \pm 0.34$ \\
\hline Diabetic & $218.3 \pm 5.5$ & $201.1 \pm 8.8$ & $58.5 \pm 2.0$ & $119.6 \pm 7.5$ & $101.6 \pm 3.9$ & $96.5 \pm 2.6$ & $1.5 \pm 0.2$ & $7.3 \pm 0.18$ \\
\hline BV high dose & $195.6 \pm 6.5^{*}$ & $114.4 \pm 1.0^{*}$ & $73 \pm 2.6^{*}$ & $99.7 \pm 9.1$ & $82.4 \pm 4.3^{*}$ & $60.4 \pm 3.7$ & $1.1 \pm 0.08$ & $8.1 \pm 0.19$ \\
\hline BV low dose & $191.8 \pm 2.7^{*}$ & $126.8 \pm 1.9^{*}$ & $57.4 \pm 1.9$ & $109 \pm 4.2$ & $77.2 \pm 6.1^{*}$ & $63.4 \pm 4.6$ & $0.85 \pm 0.09^{*}$ & $8.3 \pm 0.38$ \\
\hline Vildagliptin & $179.4 \pm 3.5^{*}$ & $111.2 \pm 3.4^{*}$ & $63.4 \pm 2.7$ & $93.7 \pm 4.3$ & $76.2 \pm 4.4^{*}$ & 46. \pm 3.6 & $0.7 \pm 0.1^{*}$ & $8.1 \pm 0.57$ \\
\hline
\end{tabular}

Values are expressed as mean \pm SE ( $n=8 /$ group)

*Significant differences between diabetic and BV low-dose-, BV high-dose-, and vildagliptin-treated groups using one way ANOVA statistical analysis test 


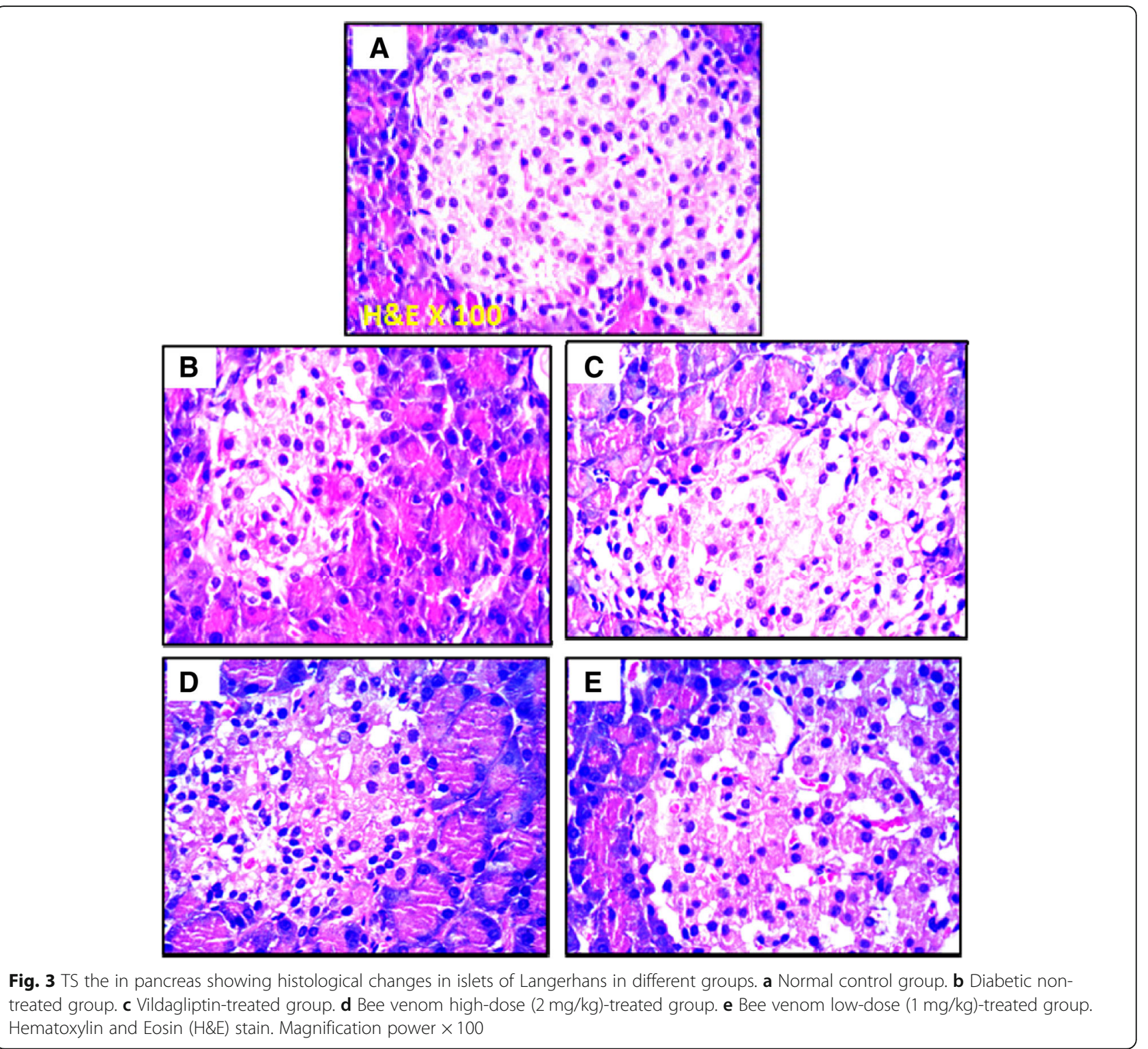

which have distinct round nuclei, and the islets covering connective tissue envelope was well detected maintaining their ordinary shape. In the diabetic animal group B, the connective tissue of islets was degenerated causing an alteration in their shape rather than discernible diminished size, and reduction in the size and existence of $\beta$-cells were also observed. Pancreatic tissue of vildagliptin-treated group $C$ showed noteworthy amelioration in islet size and dispersion with restored $\beta$-cell shape and existence.

The higher dose of BV-treated group D showed reasonable improvement in pancreatic islet size with the noticeable increased prevalence of $\beta$-cells accompanied by the existence of many vacuoles penetrating the interstitial loose connective tissue. On another hand, pancreases of lower dose BV-treated group E exhibited remarkable progression in islet structure with restored size and uniformed appearance, $\beta$-cells were obviously increased in propagation, and the generality of these cells regained their rounded shape while a little of them still had abnormal malformed shape.

\section{Discussion}

Diabetes mellitus is an endocrine disease accompanied by diverse metabolic disorders (Patel et al., 2016) and characterized by hyperglycemia and disturbances of carbohydrate, fat, and protein metabolism associated with an absolute or relative deficiency in insulin secretion or insulin action (Saravanakumar et al., 2009). Hyperglycemia, hyperlipidemia, hypertension, atherosclerosis, retinopathy, neuropathy, and nephropathy are the major complications of DM (Anfenan, 2014). Due to 
the undesirable secondary effects of the currently used hypoglycemic medications, there is a need to find another safer antidiabetic traditional medicine (Hossen et al., 2017).

Experimentally, Alloxan induced tremendous damage to pancreatic $\beta$-cells by generating ROS leading to the induction of diabetes in animals (Rohilla \& Ali, 2012). In the current experiment, the glucose level was significantly increased in the diabetic group and was associated with a significant decrease in plasma insulin level in comparison to the normal control group. These results could be due to the cytotoxic effect of alloxan which causes the destruction of islets of Langerhans and diminished insulin secretion in diabetic rats compared to the normal control group (Elgazar, Rezq, \& Bukhari, 2013). On the other hand, plasma glucose was significantly decreased in BV and vildagliptin-treated groups which were associated with a significant increase in plasma insulin level compared to the diabetic group. Similar studies had confirmed the hypoglycemic activity of BV in diabetic rats and rabbits, respectively, which is consistent with our findings (Khulan, Ambaga, \& Chimedragcha, 2015; Mousavi, Imani, Haghighi, Mousavi, \& Karimi, 2012).

The improvement of plasma insulin level may be attributed to the anti-inflammatory effect of both melittin and phospholipase A2, the two major components of BV (Park et al., 2008; Simonsson, Karlsson, \& Ahren, 2000). On another hand, the ability of melittin to depolarize plasma membranes of $\beta$-cells leading to the opening of $\mathrm{Ca}^{2+}$ channels permitting the entrance of large amounts of calcium which eventually stimulates them to secrete insulin was reported (Kim et al., 1999; Morgan \& Montague, 1984).

A significant increase in total cholesterol and triglyceride levels was noticeable in the diabetic group in comparison to the normal control group, while BV-treated groups showed a significant decrease in them and an increase in plasma HDL level. In diabetic rats, the destructive effect of alloxan on pancreatic $\beta$-cells may lead to a reduction in insulin secretion, hyperglycemia, and hyperlipidemia as consequent (Gupta \& Sharma, 2010). In the current work, the hypoglycemic and hypolipidemic effects of BV on diabetic rats were in line with Gawad et al. (2016) and Mousavi et al. (2012) and also compatible with Khulan et al. (2015) who conducted his experiment on rabbits.

Improving insulin secretion from pancreatic $\beta$-cells by BV was one of the suggested mechanisms of decreased total cholesterol level in BV-treated groups which may inhibit its absorption in the small intestine and promoting its hepatic release through bile secretion (Mousavi et al., 2012). The enzymatic action of BV phospholipase A2 on adipocyte membrane through partial lysis increased glucose transport and lipid uptake into adipose tissue and increased binding of insulin molecules (Park et al., 2008; Singh \& Ranganathan, 2012).

One of the most accepted suggestions was that BV improves insulin secretion and its action on fat cells by activation of lipoprotein lipase and hydrolysis of triglycerides which lowered triglyceride and increased plasma HDL (Khulan et al., 2015). In addition to that, lipoprotein lipase hydrolyzes triglyceride-rich lipoproteins which will release non-esterified fatty acid that will be taken up and used for metabolic energy or is re-esterified into triglyceride and stored in adipose tissue (Kusunok, Tsutsumi, Tana, Sato, \& Nakamura, 2013).

Concerning the MDA level, it was significantly increased in the diabetic group compared with the normal control group and significantly decreased after treatment with low dose BV. The anti-inflammatory effect by melittin and phospholipase A2 (Park et al., 2008; Simonsson et al., 2000) and antioxidant activities of BV that significantly had been suppressed by the pancreatic $\beta$-cell inflammation and inhibited enzymatic lipid peroxidation might be the protective mechanisms that counteracted (Gawad et al., 2016; Mousavi et al., 2012) the alloxan harmful effects on of $\beta$-cells in the pancreas (Mall, Mishra, \& Prakash, 2009). Also in another study, it was reported that BV acupuncture inhibited oxidative damage through declining ROS production (Suh et al., 2006).

CAT had been known to have antioxidant activity (Indradevi, Ilavenil, Kaleeswaran, Srigopalram, \& Ravikumar, 2012; Kodydková, Vávrová, Kocík, \& Zak, 2014) and its gene expression is downregulated by hyperglycemia (Patel, Chen, Das, \& Kavdia, 2013). In the present study, there was a significant decrease in CAT activity in the diabetic group compared to the control group which was in line with Oseni, Odesanmi, and Oladele (2015) who reported a decrease in plasma CAT activity in alloxan-induced diabetic male Wistar albino rats due to increased production of ROS and the reduction in the synthesis of this antioxidant enzyme by alloxan.

The results in the current work showed that CAT activity was significantly increased in BV-treated groups. These findings may be due to the effect of BV which declines the level of ROS that causes oxidative damage (Suh et al., 2006). These findings were in harmony with Rain (2009), who reported that BV therapy is a potent antioxidant causing a decrease in the levels of ROS, affecting GSH content, superoxide dismutase, and CAT activities. When oxidative stress exceeds the production of antioxidants as in diabetes, the CAT activity may extensively decrease as hyperglycemia is prolonged (Enefe \& Ebueih, 2018).

GSH level was decreased significantly in the diabetic group compared to the control group in the current work. The increased ROS levels in diabetic rats had created a significant decrease in GSH and the enzymatic 
antioxidants in comparison with normal control rats (Al-Azzawie \& Yaaqoob, 2016) which was in agreement with current results. Parallel to many studies, there was a significant increase in GSH level in BV low-dosetreated group compared to the diabetic group. These studies had suggested many mechanisms, like antioxidant activity of BV (Gawad et al., 2016) regeneration of GSH by glutathione reductase, which can be used as a hydrogen donor by glutathione peroxidase through the removal of hydrogen peroxide (Khan, Khan, Ahmad, \& Mushtaq, 2015) and finally, the venom-evoked increase GSH level by the effect of released catecholamine-induced by venom (Fatani et al., 2006; Murthy, As, Zare Abbas, \& Haghnazari, 2003).

TAC was significantly increased in BV high-dosetreated group in comparison to the diabetic group which was in contrast to its significant decrease in the diabetic group compared to the normal group. These findings were also in agreement with many studies in which total plasma antioxidant capacity was reduced in uncontrolled diabetes (Eleazu, Okafor, \& Ahamefuna, 2010; Polidori et al., 2000). Also, the depletion of TAC in diabetic rats could be due to the reduction in glutathione level (Oseni et al., 2015).

Hyperglycemia, as a result of diabetogenic agent alloxan, increases the production of free radicals by auto-oxidation of glucose which in turn may lead to liver cell damage and elevation of AST and ALT levels (Szkudelski, 2001). Nevertheless, AST and ALT levels were significantly increased in diabetic group animals compared to the normal control group in the current study. These results were in agreement with studies conducted by Elgazar et al. (2013) and Fernandes, Novelli, Fernandes, and Galhardi (2009) in which they reported that levels of AST and ALT were increased in the serum of diabetic rats. In contrary to that, there was a decrease in plasma AST and ALT levels in both BV-treated groups. BV had a hepatoprotective effect by inhibiting the secretion of pro-inflammatory cytokines (Park et al., 2010), which was attributed to its ability to decrease nuclear factor kappa B expression in the liver that eventually prevents hepatic injury and decreases aminotransferases (Salman, Mohi Eldin, \& Rashad, 2015).

The developed oxidative stress produced a variety of adverse effects in diabetes mellitus such as nephropathy disorders which may be due to increased production of free radicals (Hamden et al., 2008). In the present study, there was a significant increase in plasma creatinine level in the diabetic group compared to the control group. Plasma creatinine level was significantly decreased in BV low-dose-treated group compared to the diabetic group. This improvement in creatinine could be attributed to the potent antioxidant effects of BV (Rain, 2009) and protection of renal tubules from injury through upregulation of $\mathrm{T}$ regulatory cells in the kidney (Kim et al., 2013).

The histopathological observations in the present work confirmed improvement in treated groups when compared with the diabetic group. There were degeneration and vacuolization in the Langerhans's islet and $\beta$-cells, decreasing in islet size, decreasing in $\beta$-cell number, and loss of normal architecture of the islets in diabetic rats, and these data were in agreement with El-Esawy, Alghamdy, El Askary, and Elsayed (2016). So, these findings had explained the decreased insulin level and elevation of glucose concentration. As a consequence of treatment with low-dose BV and vildagliptin, the pancreas restored normal architecture, $\beta$-cell regeneration, number, and expression were enhanced, and antihyperglycemic effects had clearly appeared after 6 weeks of treatment.

The degenerative changes in the islets were compatible with the biochemical results; MDA was significantly increased in diabetic rats and was significantly decreased after treatment with BV. In the same manner, improvement in Langerhans's islet and $\beta$-cells was attributed to melittin and phospholipase A2 through suppression of pancreatic $\beta$-cell inflammation (Park et al., 2008; Simonsson et al., 2000) and restoring the activities of GSH and CAT.

\section{Conclusion}

BV could have therapeutic and protective effects on the management of biochemical and histological changes in diabetic rats. This could be either through suppression of pancreatic $\beta$-cell inflammation, antioxidant activity, promotion of insulin secretion, or promotion of the uptake of glucose in adipose tissue, with a hypolipidemic activity through improving the uptake of lipid in adipose tissue and hydrolysis of triglyceride.

\section{Abbreviations}

ALT and AST: Aminotransferases; BV: Bee venom; CAT: Catalase; DM: Diabetes mellitus; GSH: Glutathione; HDL: High-density lipoproteins; LDL: Low-density lipoproteins; MDA: Malondialdehyde; ROS: Reactive oxygen species;

TAC: Total antioxidant capacity

\section{Acknowledgements}

The authors appreciate the cooperation of Professor Mohamed Nageeb Shehatta, professor of Economic Entomology, Apiculture and Protection Department, Faculty of Environmental Agricultural Sciences, Suez Canal University.

\section{Authors' contributions}

$\mathrm{AKH}$ and REB contributed to the design of the work and interpretation of the data. DAE drafted the work. MMT contributed to the acquisition and analysis of the data. IMB contributed to the revision of the work. All authors read and approved the final manuscript.

Funding

No funding

Availability of data and materials

Data will not be shared, only by request from corresponding author. 


\section{Ethics approval and consent to participate}

Not applicable

\section{Consent for publication \\ Not applicable}

\section{Competing of interests}

The authors declare that they have no competing interest.

\section{Author details}

'Zoology Department, Faculty of Science, Port Said University, 23rd December Street, Port Said 42515, Egypt. ${ }^{2}$ Clinical Pathology Department, Faculty of Medicine, Port Said University, Port Said, Egypt.

\section{Received: 8 May 2019 Accepted: 9 August 2019}

Published online: 22 August 2019

\section{References}

Abdela, N., \& Jilo, K. (2016). Bee venom and its therapeutic values: a review. Advances Life Science and Technology., 44, 18-22.

Akarte, A. S., Srinivasan, B. P., \& Gandhi, S. A. (2012). A Novel long acting DPP-IV inhibitor PKF-275-055 stimulates $\beta$-cell proliferation resulting in improved glucose homeostasis in diabetic rats. Biochemical Pharmacology, 83, 241-252.

Al-Azzawie, H. F., \& Yaagoob, L. A. (2016). Hypoglycemic and antioxidant effects of gold nanoparticals in alloxan-induced diabetes rats. International Journal of Research in Biotechnology and Biochemistry., 6, 12-20.

American Diabetes Association (2017). Standards of Medical Care in Diabetes - 2017: Summary of Revisions. Diabetes Care, 40, 54-55.

Anfenan, M. L. K. (2014). Evaluation of nutritional and antidiabetic activity of different forms of Ginger in rats. M.E. Journal of Scientific Research, 21, 56-62.

Asmat, U., Abad, K., \& Ismail, K. (2016). Diabetes mellitus and oxidative stress - a concise review. Saudi Pharmaceutical Journal., 24, 547-553.

Das, J., Vasan, V., \& Sil, P. C. (2012). Taurine exerts hypoglycemic effect in alloxan -induced diabetic rats, improves insulin-mediated glucose transport signaling pathway in heart and ameliorates cardiac oxidative stress and apoptosis. Toxicology and Applied Pharmacology, 258, 296-308.

Eleazu, C. O., Okafor, P. N., \& Ahamefuna, I. (2010). Total antioxidant capacity, nutritional composition and inhibitory activity of unripe plantain (Musa paradisiacae) on oxidative stress in alloxan induced diabetic rabbits. Pakistan Journal of Nutrition, 9, 1052-1057.

El-Esawy, B. H., Alghamdy, A. N., El Askary, A., \& Elsayed, E. M. (2016). Histopathological evaluation of the pancreas following administration of paricalcitol in alloxan- induced diabetic Wistar rats. World Journal of Pharmacy and Pharmaceutical Sciences., 5, 189-198.

Elgazar, A. F., Rezq, A. A., \& Bukhari, H. M. (2013). Anti-hyperglycemic effect of Saffron extract in alloxan-induced diabetic rats. European Journal of Biological Sciences, 5, 14-22.

Enefe, N. G., \& Ebueih, O. A. (2018). Antioxidant Enzymes and lipid peroxidation in alloxan-induced diabetic rabbits. Animal and Veterinary Sciences., 6(2), 27-34.

Fatani, A. J., Al-Zuhair, H. A., Yaquob, H. I., Abdel-Fattah, A. A., El-Sayed, M. I., \& El -Sayed, F. A. (2006). Protective effects of the antioxidant Ginkgo biloba extract and the protease inhibitor aprotinin against Leiurus quinquestriatus venominduced tissue damage in rats. Journal of Venomous Animals and Toxins Including Tropical Diseases, 12, 255-275

Fernandes, A. A. H., Novelli, E. L. B., Fernandes, J. A., \& Galhardi, C. M. (2009). Effect of naringerin on biochemical parameters in the streptozotocin-induced diabetic rats. Brazilian Archives of Biology and Technology. Brazilian Archives of Biology and Technology, 52, 51-59.

Gawad, S. A., Fikry, H., Amin, M. M., Elmahdi, A. R., \& Elaziz, D. A. (2016). Effect of apitherapy on the pancreas and liver of streptozotacin induced diabetic rats: a biochemical and histological study. European Journal of Pharmaceutical and Medical Research., 3, 555-565.

Gupta, V., \& Sharma, M. (2010). Protective effect of Cinnamomum tejpata on lipid peroxide formation in isolated rat liver homogenate. Current Research Journal of Biological Sciences, 2, 246-249.

Hamden, K., Carreau, S., Lajm, S., Aloulou, D., Kchaou, D., \& Elfeki, A. (2008). Hyperglycaemia, stress oxidant, liver dysfunction and histological changes in diabetic male rat pancreas and liver: protective effect of 17 beta-estradiol. Steroids., 94, 495-501.
Hossen, M. S., Gan, S. H., \& Khalil, M. I. (2017). Melittin, a potential natural toxin of crude bee venom: probable future arsenal in the treatment of diabetes mellitus. Journal of Chemistry, 2018, 1-7.

Indradevi, S., Ilavenil, S., Kaleeswaran, B., Srigopalram, S., \& Ravikumar, S. (2012) Ethanolic extract of Crinum asiaticum attenuates hyperglycemia-mediated oxidative stress and protects hepatocytes in alloxan induced experimental diabetic rats. Journal of King Saud University-Science., 24, 171-177.

Khan, A. N., Khan, R. A., Ahmad, M., \& Mushtaq, N. (2015). Role of antioxidant in oxidative stress and diabetes mellitus. Journal of Pharmacognosy and Phytochemistry., 3, 217-220.

Khulan, T. S., Ambaga, M., \& Chimedragcha, C. H. (2015). Effect of honey bee venom (Apis mellifera) on hyperglycemia and hyperlipidemia in alloxan induced diabetic rabbits. Journal of Diabetes Metabolism, 6, 2-4.

Kim, H., Lee, G., Park, S., Chung, H. S., Lee, H., Kim, J. Y., \& Bae, H. (2013). Bee venom mitigates cisplatin-induced nephrotoxicity by regulating $\mathrm{CD} 4^{+} \mathrm{CD} 25^{+}$Foxp $^{+}{ }^{+}$regulatory $\mathrm{T}$ cells in mice. Evidence-based Complementary and Alternative Medicine, 2013, 1-10.

Kim, J. Y., Cho, S. H., Kim, Y. W., Jang, E. C., Park, S. Y., Kim, E. J., \& Lee, S. K. (1999). Effects of BCG, lymphotoxin and bee venom on insulitis and development of IDDM in non-obese diabetic mice. Journal of Korean Medical Science, 14, 648-652

Kodydková, J., Vávrová, L., Kocík, M., \& Zak, A. (2014). Human catalase, its polymorphisms, regulation and changes of its activity in different diseases. Folia Biologica (Praha)., 60, 153-167.

Kusunok, M., Tsutsumi, K., Tana, C., Sato, D., \& Nakamura, T. (2013). Lipoprotein lipase activation improves the cachexia and obesity. Journal of Obesity and Weight Loss Therapy, 3, 1-6.

Mall, G. K., Mishra, P. K., \& Prakash, V. (2009). Antidiabetic and hypolipidemic activity of Gymnema sylvestre in alloxan induced diabetic rats. Global Journal of Biotechnology \& Biochemistry, 4, 37-42.

Morgan, N. G., \& Montague, W. (1984). Stimulation of insulin secretion from isolated rat islets of Langerhans by melittin. Bioscience Reports, 4, 665-671.

Mousavi, S. M., Imani, S., Haghighi, S., Mousavi, S. E., \& Karimi, A. (2012). Effect of Iranian honey bee (Apis mellifera) venom on blood glucose and insulin in diabetic rats. Journal of Arthropod-Borne Diseases, 6, 136-143.

Murthy, K. R., As, D., Zare Abbas, M., \& Haghnazari, L. (2003). Investigations on the role of insulin and scorpion antivenom in scorpion envenoming syndrome. Journal of Venomous Animals and Toxins Including Tropical Diseases, 9, 202-238.

Oseni, O. A., Odesanmi, O. E., \& Oladele, F. C. (2015). Antioxidative and antidiabetic activities of watermelon (Citrullus lanatus) juice on oxidative stress in alloxan-induced diabetic male Wistar albino rats. Nigerian Medical Journal, 56, 272-277.

Park, H. J., Lee, H. J., Choi, M. S., Son, D. J., Song, H. S., Song, M. J., ... Hong, J. T. (2008). JNK pathway is involved in the inhibition of inflammatory target gene expression and NF-kappa B activation by melittin. Journal of Inflammation, 5, 5-7.

Park, J., \& Jang, H. J. (2017). Anti-diabetic effects of natural products: an overview of therapeutic strategies. Molecular \& Cellular Toxicology, 13, 1-20

Park, J. H., Kim, K. H., Kim, S. J., Lee, W. R., Lee, K. G., \& Park, K. K. (2010). Bee venom protects hepatocytes from tumor necrosis factor-alpha and actinomycin D. Archives of Pharmacal Research, 33, 215-223.

Patel, D., Gidwani, B., Sarwa, K., Kaur, C. D., Dhongade, H. J., Sahu, P., \& SAHU, V. (2016). A comprehensive review on the anti-diabetic activity of Momordica charantia and Syzygium cumini seeds. International Journal of Biology, Pharmacy and Allied Sciences, 5, 1561-1575.

Patel, H., Chen, J., Das, K. C., \& Kavdia, M. (2013). Hyperglycemia induces differential change in oxidative stress at gene expression and functional levels in HUVEC and HMVEC. Cardiovascular Diabetology, 12, 142-146.

Polidori, M. C., Mecocci, P., Stahl, W., Parent, B., Cecchetti, R., Cherubini, A., Senin, U. (2000). Plasma levels of lipophilic antioxidants in very old patients with type 2 diabetes. Diabetes/Metabolism Research and Reviews, 16, 15-19.

Raghuraman, H., \& Chattopadhyay, A. (2007). Melittin: a membrane-active peptide with diverse functions. Bioscience Reports, 27, 189-223.

Rain, D. (2009). Bee venom therapy for inflammatory conditions: historical and recent trends. Journal of the American Apitherapy Society, 16, 1-11.

Rashid, K. Das, J., \& Sil, P. C. (2013). Taurine ameliorate alloxan induced oxidative stress and intrinsic apoptotic pathway in the hepatic tissue of diabetic rats. Food and Chemical Toxicology, 51, 317-329.

Rohilla, A., \& Ali, S. (2012). Alloxan induced diabetes: mechanisms and effects. International Journal of Research in Pharmaceutical and Biomedical Sciences, 3, 819-823. 
Roudbari, L., \& Imani, S. (2012). The effects of Androctonus crassicauda scorpion venom in the treatment of diabetes mellitus type 1 in animal models. Annals of Biological Research, 3, 5782-5785.

Roy, S., Saha, S., \& Pal, P. (2015). Insect natural products as potential source for alternative medicines-a review. World Scientific News., 19, 80-94.

Salman, M. M., Mohi Eldin, M. M., \& Rashad, N. (2015). Physiological effects of bee venom and propolis on irradiated albino rats. Danish Journal of Agriculture and Animal Sciences., 2015, 11-21.

Sandu, M. M., Protasiewicz, D. C., Firănescu, A. G., Lăcătușu, E. C., Bîcu, M. L., \& Moța, M. (2016). Data regarding the prevalence and incidence of diabetes mellitus and prediabetes. Romanian Journal of Diabetes Nutrition and Metabolic Diseases, 23, 95-103.

Saravanakumar, A., Venkateshwaran, K., Vanitha, J., Ganesh, M., Vasudevan, M., \& Sivakumar, T. (2009). Evaluation of antibacterial activity, phenol and flavonoid contents of Thespesia populnea flower extracts. Pakistan Journal of Pharmaceutical Sciences, 22, 282-286.

Sforcin, J. M., Bankova, V., \& Kuropatnicki, A. K. (2017). Medical benefits of honeybee products. Evidence-based Complementary and Alternative Medicine, 2017, 1-2.

Shabeer, J., Srivastava, R. S., \& Singh, S. K. (2009). Antidiabetic and antioxidant effect of various fractions of Phyllanthus simplex in alloxan diabetic rats. Journal of Ethnopharmacology, 124, 34-38.

Simonsson, E., Karlsson, S., \& Ahren, B. (2000). Islet phospholipase A2 activation is potentiated in insulin resistant mice. Biochemical and Biophysical Research Communications, 272, 539-543.

Singh, J., \& Ranganathan, R. (2012). Quantitation of lysolipids, fatty acids and phospholipase A2 activity and correlation with membrane polarity. Journal of Lipid Research, 53, 1993-2001.

Suh, S. J., Kim, K. S., Kim, M. J., Chang, Y. C., Lee, S. D., Kim, M. S., \& Kim, C. H. (2006). Effects of bee venom on protease activities and free radical damages in synovial fluid from type II collagen-induced rheumatoid arthritis rats. Toxicology In Vitro, 20, 1465-1471.

Szkudelski, T. (2001). The mechanism of alloxan and streptozotocin action in $\beta$ - cells of the rat pancreas. Physiological Research, 50, 537-546.

Thakare, V., Shende, S. S., Shirure, P. A., \& Swami, O. C. (2017). Role of conventional oral antidiabetic drugs in management of type 2 diabetes mellitus. International Journal of Research in Medical Sciences, 5, 749-758.

World Health Organization (2016). Global report on diabetes. World Health Organization, 2016, 1-88.

Yadav, J. P., Saini, S., Kalia, A. N., \& Dangi, A. S. (2008). Hypoglycemic and hypolipidemic activity of ethanolic extract of Salvadora oleoides in normal and alloxan-induced diabetic rats. Indian Journal of Pharmacology, 40, 23-27.

\section{Publisher's Note}

Springer Nature remains neutral with regard to jurisdictional claims in published maps and institutional affiliations.

\section{Submit your manuscript to a SpringerOpen ${ }^{\circ}$ journal and benefit from:}

- Convenient online submission

- Rigorous peer review

- Open access: articles freely available online

- High visibility within the field

- Retaining the copyright to your article

Submit your next manuscript at $\boldsymbol{\nabla}$ springeropen.com 